\title{
Increased fecundity of malathion-specific resistant beetles in absence of insecticide pressure
}

\author{
L Arnaud ${ }^{1}$, Y Brostaux ${ }^{2}$, LK Assié ${ }^{1}$, C Gaspar $^{1}$ and E Haubruge ${ }^{1}$ \\ ${ }^{1}$ Department of pure and applied Zoology, Gembloux Agricultural University - 2, Gembloux, Belgium; ${ }^{2}$ Department of Statistic \\ and Computer Science, Gembloux Agricultural University - 2, Gembloux, Belgium
}

Despite that resistance frequency is assumed to decline when selective pressure is relaxed, the stability of resistance frequency has been observed in some insects in the absence of insecticide. In the red flour beetle, Tribolium castaneum, the first case of malathion-resistance was reported in the early 1960s. The malathion-specific resistant phenotype has now almost completely replaced the susceptible one in red flour beetle populations. In the present study, several life-history traits that could influence the fitness of the insects were compared between insecticide-susceptible and malathion-specific resistant populations of the red flour beetle. On average, egg fertility and egg-to-adult develop- ment time did not differ between susceptible and resistant populations. However, the fecundity of resistant females was greater than that of susceptible ones. Generally, differences in development time between insecticide resistant and susceptible populations are considered as having more effect on fitness than do differences in fecundity. However, the observed increased female fecundity may participate, in combination with the previously observed increased male reproductive success, to the development and the stability of malathion-specific resistance in $T$. castaneum.

Heredity (2002) 89, 425-429. doi:10.1038/sj.hdy.6800167

Keywords: Tribolium castaneum; flour beetle; insecticide resistance; fitness; selection

\section{Introduction}

The extensive use of insecticide to control insect pests has provided a dramatic illustration of evolution in natural populations. Once insecticide resistance has been selected in a population, different factors will influence the speed at which the frequency of resistance allele(s) will change. Ecology and life histories may dramatically alter the responsiveness to the selection that leads to insecticide resistance (Georghiou and Taylor, 1986). It is not surprising that resistant and susceptible strains differ in properties other than their adaptation to insecticides, such as development time, fecundity and fertility. Since resistant individuals were not common prior to selection, it is generally assumed that resistant genotypes must have a reproductive disadvantage in the absence of pesticides. Thus, when selective pressure is relaxed, there may be intense selection against alleles conferring insecticide resistance, and these alleles will decline in frequency (Crow, 1957; Carrière et al, 1994; Carrière and Roff, 1995; McKenzie, 1996). Although the majority of fitness studies show this pattern, in some cases, there is no fitness difference in the absence of treatment between resistant and susceptible strains, and the resistant strains sometimes have a fitness advantage. This absence of a trade-off between fitness and insecticide resistance could result from the absence of pleiotropic costs of the alleles

Correspondence: Dr E Haubruge, Department of pure and applied Zoology, Gembloux Agricultural University - 2, passage des déportés, B5030 Gembloux, Belgium. E-mail: haubruge.e@fsagx.ac.be

Received 14 December 2001; accepted 24 July 2002 involved in resistance, from the selection of modifiers that ameliorate the fitness of resistant genotypes in the absence of insecticide (see McKenzie, 1996, and references therein), or from the replacement of the resistance alleles by less costly resistance alleles (Guillemaud et al, 1998; Raymond et al, 2001).

As a consequence of the intensive use of malathion in grain storage since the late 1950s, the first case of malathion-resistance in Tribolium castaneum (Herbst) (Coleoptera, Tenebrionidae) was reported in 1961 (Parkin et al, 1962). By 1974, this phenomenon was regarded as a common attribute of the species (Champ and Dyte, 1976). Although malathion usage has declined or has even been abandoned in some countries in the early seventies, because of the widespread occurrence of malathion-specific resistance in red flour beetle populations (Champ, 1984), this resistance mechanism is very stable in T. castaneum wild populations. Moreover, the malathion-resistant phenotype has almost completely replaced the susceptible one (Georghiou and Lagunes-Tejeda, 1991; Subramanyam and Hagstrum, 1996 for reviews). However, malathion is still widely used to control stored product insects (White and Leesch, 1996).

In $T$. castaneum, no trade-off has been reported between malathion-specific resistance and the fitness of the insects (Beeman and Nanis, 1986; Haubruge and Arnaud, 2001). In addition, it is likely that the genetic background of the insects does not influence their fitness (Haubruge and Arnaud, 2001). Both of these observations may explain the widespread occurrence of malathion-specific resistance in this species. The world-wide migration of stored product insects through the food and cereal trade may 
have favoured the development of malathion-specific resistance in susceptible populations, resulting in an inability to control these populations with malathion.

Despite the effect of malathion-specific resistance on fitness of the red flour beetle being studied by different authors (Beeman and Nanis, 1986; White and Bell, 1988; Haubruge and Arnaud, 2001), none has focussed on the biological parameters giving a reproductive advantage to the resistant individuals. Also, most of these studies were conducted on a few susceptible and resistant strains.

In this study, we examined several life-history traits that could influence the fitness of the insects. Egg fertility, female fecundity and egg-to-adult development time were compared between several insecticide-susceptible and malathion-specific resistant populations of the red flour beetle that originated from different geographic areas.

\section{Materials and methods}

\section{Tribolium populations}

Twelve red flour beetle strains were used in this study (Table 1). The insects were reared on whole wheat flour enriched with brewer's yeast (10:1-wt:wt) and kept in the dark at $30 \pm 3^{\circ} \mathrm{C}$ and $60 \pm 5 \%$ relative humidity (r.h.). These strains have been cultured without pesticide exposure for several years.

\section{Malathion susceptibility and characterisation of the resistance}

The following bio-assay was conducted to discriminate between malathion-specific resistance and malathion non-specific resistance. A dose of insecticide that would kill all individuals of a susceptible population was used as the discriminating dose. We used a $1 \%$ (wt:vol) malathion solution as discriminating dose. Following a 24-h starvation period, 50 adults were placed in contact with treated papers (350 $\mu \mathrm{l}$ per filter paper, $\varnothing 55 \mathrm{~mm})$ in a Petri dish. For every strain, the number of dead beetles was scored after $5 \mathrm{~h}$ and compared to the mortality of the control strain (Asm, 100\% mortality - Haubruge et al, 1997). A synergist was used with strains in which resistant individuals were detected. Papers impregnated with the synergist solution in acetone (10\%, wt:vol) were placed in a Petri dish with 50 adult beetles for 24 hours. The synergist was triphenyl phosphate (TPP - >99\%

Table 1 Populations of the red flour beetle, Tribolium castaneum (Coleoptera, Tenebrionidae), and their origin

\begin{tabular}{ll}
\hline Populations & Origin \\
\hline Argyle & Manitoba, Canada, 1992 \\
Asm & Abidjan, Ivory Coast, 1989 \\
Ex-Maff & Maff, UK, 1991 \\
Ga-1 & Georgia, USA, 1980 \\
Kano & Nigeria, 1961 \\
Lab-S & Kansas, USA, 1960 \\
Landmark & Manitoba, Canada, 1991 \\
Mozambique & Mozambique, 1976 \\
Paulo d'Amico & British Columbia, Canada, 1976 \\
PRm & Naphin, Philippines, 1976 \\
Rio Desago & New Brunswick Canada, 1976 \\
Waseco & Minnesota, USA, 1982 \\
\hline
\end{tabular}

purity, Merck-Schuchardt, München, Germany), a carboxylesterase inhibitor (Dyte and Rowlands, 1968). Papers impregnated with TPP were then replaced by filter papers treated with the acetonic solution of malathion at the discriminating dose. After $5 \mathrm{~h}$, adult mortality was scored. Two replications were performed for every bioassay.

\section{Life history traits: fertility, fecundity and development time}

Egg fertility: The fertility of eggs laid by females was estimated for the different strains. One hundred adults were placed for $24 \mathrm{~h}$ in a $150 \mathrm{~mm}$ petri dish with rearing medium sieved at $0.2 \mathrm{~mm}$. The eggs laid during that period were removed from the medium. Ninety-six eggs were randomly selected and placed individually in a 96well microlitre plate. After 6 days, the number of hatched egg was scored. This experiment was replicated two times.

Fecundity: Beetles of every T. castaneum strain were sexed as pupae and maintained by sex in a $55 \mathrm{~mm}$ Petri dish with $5 \mathrm{~g}$ of the rearing medium. After 20 days, 30 males marked with a black pencil and 30 females were placed together in a $90 \mathrm{~mm}$ Petri dish with $20 \mathrm{~g}$ of rearing medium for 4 days. The males were then removed and the females remained in the dish for 5 more days. Afterwards, females were placed individually in a $55 \mathrm{~mm}$ Petri dish with $5 \mathrm{~g}$ of the rearing medium sieved at $0.2 \mathrm{~mm}$. After 2 days, the number of eggs laid by the female was recorded. Females were placed in a new dish for a second 2-day period. The numbers of eggs laid during the two egg laying periods were pooled prior to statistical analysis.

Development time: One hundred adults were placed for $24 \mathrm{~h}$ in a $150 \mathrm{~mm}$ Petri dish with rearing medium sieved at $0.2 \mathrm{~mm}$. One hundred eggs laid during that period were placed at $30 \pm 3^{\circ} \mathrm{C}$ and $60 \pm 5 \%$ r.h. in a $55 \mathrm{~mm}$ Petri dish with $20 \mathrm{~g}$ of rearing medium. Three weeks later, emerging adults were scored at least once every day and mean developmental time of each of the populations was calculated. The experiment was replicated three times.

\section{Statistical analysis}

The data were statistically analysed with Minitab (version 12.2 for Windows - Minitab, 1998) and SAS (version 8.01 for windows - SAS, 1999). Although we present untransformed for clarity (mean \pm standard error), the egg fertility data were arcsin-transformed prior to the analysis $\left(Y=2 \times \arcsin (X)^{1 / 2}\right)$.

\section{Results}

\section{Malathion susceptibility and characterisation of the resistance}

The malathion susceptibility of the different flour beetle populations, and the characterisation of the resistance mechanism involved in the resistant populations are presented in Table 2. We observed that the mechanism of resistance was malathion-specific in every resistant strain. All the malathion-resistant beetles tested died 
Table 2 Malathion susceptibility of the Tribolium castaneum populations with and without synergist (triphenylphosphate TPP)

\begin{tabular}{lcc}
\hline \multirow{2}{*}{ Populations } & \multicolumn{2}{c}{ Mortality (in\%) } \\
\cline { 2 - 3 } & without TPP & with TPP \\
\hline Susceptible & & \\
Asm & 100 & - \\
Ex-Maff & 100 & - \\
Lab-S & 100 & - \\
Mozambique & 100 & - \\
Resistant & & 100 \\
Argyle & 0 & 100 \\
Ga-1 & 0 & 100 \\
Kano & 0 & 100 \\
Landmark & 0 & 100 \\
Paulo d'Amico & 0 & 100 \\
PRm & 0 & 100 \\
Rio Desago & 0 & 100 \\
Waseco & 0 & \\
\hline
\end{tabular}

${ }^{a}$ At the discriminating dose of malathion (1\%) after 5 h-exposure.

when they had previously been in contact with TPP. These populations were thus retained for the comparison of life history traits between susceptible and resistant populations.

\section{Life history traits}

The observations for egg fertility, female fecundity and egg-to-adult development time are shown in Table 3. There was a significant difference within the resistant/susceptible groups between the different populations for the three parameters examined: fertility (twoway nested anova, $\mathrm{F}_{10,12}=3.16, P=0.031$ ), female fecundity (two-way nested anova, $\mathrm{F}_{10,348}=13.29, P<0.001$ ) and development time (three-way unbalanced nested anova, $\left.F_{10,24}=19.15, P<0.001\right)$. Despite fertility was different between the strains, only one group was underscored with the Newman and Keuls' test (d.f. = 12, mean s.e. $=0.014$, Table 3). Also, on average, egg fertility did not differ between resistant and susceptible populations (two-way nested anova, $\mathrm{F}_{1,12}=0.86, P=0.375$ ). The multiple range test (Newman and Keuls, d.f. $=24$, mean s.e. $=15.5$ ) detected six overlapping groups for development time (Table 2). The Ex-Maff (malathion susceptible) and Paulo d'Amico (malathion resistant) populations were the only populations belonging to only one group and possessed respectively the smallest and the longest development time. Resistant and susceptible populations were observed in the intermediary groups. Despite these differences, on average, resistant and susceptible individuals were found to possess similar development time (three-way unbalanced nested anova, $\mathrm{F}_{1,10}=0.73, P=$ $0.412)$. Five groups were observed for female fecundity (Newman and Keuls' test, d.f. $=347$, mean s.e. $=131.0$, Table 2). Two of them overlapped. Females of the susceptible populations Ex-Maff and Mozambique were the less fecund. The most fecund females were found in the resistant population Kano. On average, resistant females were significantly more fecund than susceptible ones (two-way nested anova, $\mathrm{F}_{1,348}=15.72, P=0.003$ ).

\section{Discussion}

Malathion-resistant strains of stored-product insects often show reduced fitness compared to susceptible ones in the absence of selective pressure (Halliday, 1990; White and Bell, 1990; Mason, 1998). However, no negative effect on fitness resulting from the resistant allele(s) was observed in some stored product beetle populations (Beeman and Nanis, 1986; Haubruge and Arnaud, 2001). Similar trends have been observed in malathion-specific resistant strains of Anisopteromalus calandrae and Bracon hebetor, two parasitoid wasps commonly found in the ecosystem of stored-products (Baker, 1995; Baker et al, 1998).

In this study, examining several biological parameters of four susceptible and eight malathion-resistant populations originating from different geographic areas, we did not observe any significant difference in egg fertility between the resistant and the susceptible populations.

Table 3 Egg fertility, female fecundity and egg to adult development time of susceptible and malathion-specific resistant populations of Tribolium castaneum

\begin{tabular}{|c|c|c|c|}
\hline Populations & Fertility $(n=2 \times 96)^{1}$ & Fecundity $(n=30)^{2,3}$ & Development time ${ }^{2,4}$ \\
\hline \multicolumn{4}{|l|}{ Susceptible } \\
\hline Asm & $78.7 \pm 3.0 \mathrm{a}$ & $30.9 \pm 3.2 b$ & $27.3 \pm 0.1(238) \mathrm{bcd}$ \\
\hline Ex-Maff & $84.4 \pm 2.6 \mathrm{a}$ & $18.0 \pm 1.7 \mathrm{a}$ & $26.2 \pm 0.1(277) \mathrm{a}$ \\
\hline Lab-S & $88.0 \pm 2.3 \mathrm{a}$ & $30.9 \pm 2.8 b$ & $28.3 \pm 0.1(276) \mathrm{de}$ \\
\hline Mozambique & $92.7 \pm 1.9 \mathrm{a}$ & $14.3 \pm 1.0 \mathrm{a}$ & $27.3 \pm 0.1(216) \mathrm{bcd}$ \\
\hline Average & $85.9 \pm 4.5$ & $23.5 \pm 3.8$ & $27.3 \pm 0.5$ \\
\hline \multicolumn{4}{|l|}{ Resistant } \\
\hline Argyle & $93.2 \pm 1.8 \mathrm{a}$ & $42.7 \pm 1.3 \mathrm{de}$ & $26.3 \pm 0.1(294) \mathrm{ab}$ \\
\hline Ga-1 & $86.5 \pm 2.5 \mathrm{a}$ & $41.2 \pm 1.7 \mathrm{~cd}$ & $29.0 \pm 0.1(280)$ ef \\
\hline Kano & $89.6 \pm 2.2 \mathrm{a}$ & $50.5 \pm 2.7 \mathrm{e}$ & $27.4 \pm 0.1(274) \mathrm{cd}$ \\
\hline Landmark & $92.7 \pm 1.9 \mathrm{a}$ & $43.7 \pm 1.6 \mathrm{de}$ & $26.7 \pm 0.1(297) a b c$ \\
\hline Paulo d'Amico & $89.1 \pm 2.2 \mathrm{a}$ & $28.5 \pm 2.0 \mathrm{~b}$ & $29.3 \pm 0.1(288) \mathrm{f}$ \\
\hline PRm & $85.9 \pm 2.5 \mathrm{a}$ & $35.7 \pm 1.8 \mathrm{bc}$ & $28.3 \pm 0.1(217) \mathrm{de}$ \\
\hline Rio Desago & $91.7 \pm 2.0 \mathrm{a}$ & $45.4 \pm 2.6 \mathrm{de}$ & $28.3 \pm 0.1(272) \mathrm{de}$ \\
\hline Waseco & $80.2 \pm 2.9 a$ & $49.1 \pm 1.4 \mathrm{de}$ & $27.2 \pm 0.1(244) b c$ \\
\hline Average & $88.6 \pm 2.2$ & $42.1 \pm 2.7$ & $27.8 \pm 0.4$ \\
\hline
\end{tabular}

1: mean percentage of larval emergence \pm s.e., 2: mean \pm s.e., 3: number of eggs laid during 4 days (two periods of 2 days), 4: in days, (number of adults observed). In the same column, data followed by a different letter a significantly different (Newman and Keuls multiple comparison test, $P<0.05)$. 
Resistant adults did develop more slowly than susceptible ones, but the difference was weak and not significant. In addition, on average, resistant females were 1.8 times more fecund than susceptible ones. Differences in development time between insecticide resistant and susceptible populations are generally considered as having more effect on the reproductive potential of the individuals than differences in fecundity (Roush and Plapp, 1982; Roush and Croft, 1986). However, in some circumstances more fecund individuals may be favoured by natural selection (Lloyd, 1979). Thus, the development and stability of malathion-specific resistance in T. castaneum may have been favoured by increased fecundity of resistant females. A similar trend, ie increased female fecundity and resistance stability, was observed in malathion-resistant house flies, Musca domestica (Keiding, 1967) and organophosphate-resistant Myzus persicae (Williams et al, 1998).

It was previously observed that malathion-specific resistant male $T$. castaneum have a better reproductive success than susceptible ones when placed in competition for susceptible female fertilisation. This phenomenon was explained by pre- or post-copulatory female choice for these males, or by a higher ability of these males at mating or in sperm competition (Arnaud and Haubruge, Evolution - accepted for publication). The present data suggest that it is not only the resistant males that have a reproductive advantage. Resistant females, by laying more eggs than susceptible ones, increase the fitness of resistant populations. The higher female fecundity, in combination with better male reproductive success, may have participated in the development and the stability of malathion-specific resistance in this species.

The stability of insecticide resistance was found to be the result of subsequent modification of the insect genome (Roush and McKenzie, 1987; McKenzie, 1996; Guillemaud et al, 1998; Raymond et al, 2001). In the sheep blowfly, Lucilia cuprina, there is a fitness cost associated with an allele coding for resistance to diazinon. But, following the intensive use of diazinon, a modifier gene has been selected in the field which completely suppresses this cost. As a result, resistant insects carrying the modifier gene are equally fit as the susceptible insects (see McKenzie, 1996 for a review of the phenomenon). The genes involved in the resistance of the mosquito Culex pipiens to organophosphate insecticides are costly in fitness terms. However, at one resistance locus, a reduction of cost, driven by allele replacement and not by selection of modifiers has been observed (Guillemaud et al, 1998; Raymond et al, 2001). If such modifier genes or allele replacement occurred in $T$. castaneum malathion-specific resistance, due to the intensive selective pressure with malathion, the increased fecundity of resistance insects may be explained as a pleiotropic effect of the modifier gene or the less costly resistance allele; giving them a reproductive advantage compared to susceptibles.

World trade of cereal products implies the dispersal of pests from different geographic areas (Freeman, 1967) and therefore of different selective life histories, genetic background and insecticide resistance status. This may result in the introduction of resistant insects in silos already contaminated by susceptible insects (Dyte, 1979). T. castaneum is distributed world-wide and is the most common stored product beetle occurring in grain stores and flour mills (Sokoloff, 1974). The likelihood of popu- lations originating from different geographic areas mixing together is therefore high. As malathion-specific resistance is inherited as a co-dominant trait (Haubruge and Arnaud, 2001), heterozygous and homozygous resistant insects are thus resistant to malathion. Moreover, heterozygous insects are fitter than the homozygous ones (White and Bell, 1988; Haubruge and Arnaud, 2001). Both factors may increase the speed at which malathionspecific resistance develops once resistant insects migrate in a susceptible population.

\section{Acknowledgements}

We are grateful to J McKenzie, J Brookfield and the anonymous referees for providing helpful comments on the manuscript. We thank R Beeman, P Golob, F FleuratLessard, N White and D Wool for providing the Tribolium strains and M Khamkham for technical assistance. This work was founded by a PhD grant from the FRIA (Fonds pour la Formation à la Recherche dans l'Industrie et dans l'Agriculture) to L Arnaud. L Arnaud is a postdoctoral researcher of the FNRS (Fonds National de la Recherche Scientifique).

\section{References}

Arnaud L, Haubruge E. Insecticide resistance enhances male reproductive success in a beetle. Evolution (accepted for publication)

Baker JE (1995). Stability of malathion-resistance in two Hymenopterous parasitoids. J Econ Entomol 88: 232-236.

Baker JE, Perez-Mendoza J, Beeman RW, Throne JE (1998). Fitness of a malathion-resistant strain of the parasitoid Anisopteromalus calandrae (Hymenoptera: Pteromalidae). J Econ Entomol 91: 50-55.

Beeman RW, Nanis SM (1986). Malathion resistance alleles and their fitness in the red flour beetle (Coleoptera: Tenebrionidae). J Econ Entomol 79: 580-587.

Carrière Y, Roff DA (1995). Change in genetic architecture resulting from the evolution of insecticide resistance: a theoretical and empirical analysis. Heredity 75: 618-629.

Carrière Y, Deland JP, Roff DA, Vincent C (1994). Life-history costs associated with the evolution of insecticide resistance. Proc R Soc Lond B 258: 35-40.

Champ BR (1984). Pesticide resistance in stored product insects. In: Champ BR (ed), Proc Aust Dev Assist Course on Preservation of Stored Cereals: Canberra, Australia, 1981. pp. 681-690.

Champ BR, Dyte CE (1976). Report of the FAO global survey of pesticides susceptibility of stored grain pests. Food and agriculture organization of the United Nations, Plant Production and Protection, series no. 5, FAO Rome.

Crow JF (1957). Genetics of insect resistance to chemicals. Ann Rev Entomol 2: 227-246.

Dyte CE (1979). The importation of insecticide-resistant strains of stored-product pests. Ann Appl Biol 91: 414-417.

Dyte CE, Rowlands DG (1968). The metabolism and synergism of malathion in resistant and susceptible strains of Tribolium castaneum (Herbst) (Coleoptera, Tenebrionidae). J Stored Prod Res 4: 157-173.

Freeman JA (1967). Problems of infestation of commodities carried by sea with special references to imports into Great Britain. EPPO Publication, Series A, No 46E, Stored Product Conference, Lisbon, 1967.

Georghiou GP, Lagunes-Tejeda A (1991). The occurrence of resistance to pesticides in arthropods: an index of cases reported through 1989 , FAO, Roma.

Georghiou GP, Taylor CE (1986). Factor influencing the evolution of resistance. In: Pesticide resistance: strategies and tactics 
for management: National Academy Press: Washington: USA. pp 157-169.

Guillemaud T, Lenormand T, Bourguet D, Chevillon C, Pasteur N, Raymond M (1998). Evolution of resistance in Culex pipiens: allele replacement and changing environment. Evolution: 52: 443-453.

Halliday WR (1990). Comparative fitness of malathion-resistant and susceptible Indian meal moth. J Econ Entomol 70: 239-245.

Haubruge E, Arnaud L (2001). Fitness consequences of malathion-specific resistance in the red flour beetle and selection for resistance in absence of insecticide. I Econ Entomol 94: 552-557.

Haubruge E, Arnaud L, Mignon J (1997). The impact of sperm precedence in malathion resistance transmission in population of the red flour beetle Tribolium castaneum (Herbst) (Coleoptera, Tenebrionidae). J Stored Prod Res 33: 143-146.

Keiding J (1967). Persistence of resistant populations after the relaxation of the selection pressure. World Rev Pest Contr 6: 115-130.

Lloyd JE (1979). Mating behaviour and natural selection. Fla Entomol 62: 17-34.

Mason PL (1998). Selection for and against resistance to insecticides in the absence of insecticide: a case study of malathion resistance in the saw-toothed grain beetle, Oryzaephilus surinamensis (Coleoptera: Silvanidae). Bull Entomol Res 88: 177-188.

McKenzie JA (1996). Ecological and evolutionary aspects of insecticide resistance. RG Landes Company, Austin and Academic Press: San Diego.

Minitab (1998). Version 12.2 sous windows. Minitab Inc., State College, PA, USA.

Parkin EA Scott EIC, Forester R (1962). Increase resistance of stored-product insects to insecticides. The resistance of field strains of beetles. (c) Tribolium castaneum. Pest Infest Res 21: 34-35.

Raymond M, Berticat C, Weill M, Pasteur N, Chevillon C (2001). Insecticide resistance in the mosquito Culex pipiens: what have we learned about adaptation? Genetica 112-113: 287-296.
Roush RT, Croft BA (1986). Experimental population genetics and ecological studies of pesticide resistance in insects and mites. In: Pesticide resistance: strategies and tactics for management. National Academy Press: Washington, USA. pp 257270.

Roush RT, McKenzie JA (1987). Ecological genetics of insecticide and acaricide resistance. Ann Rev Entomol 32: 361-380.

Roush RT, Plapp FW (1982). Effects of insecticide resistance on biotic potential of the house fly (Diptera: Muscidae). J Econ Entomol 75: 708-713.

SAS (1999). Version 8.01 on Windows. SAS Institute Inc., Cary, NC, USA.

Subramanyam B, Hagstrum DW (1996). Resistance measurement and management. In: Subramanyam B, Hagstrum DW (eds), Integrated Management of Insects in Stored Products, Marcel Dekker, Inc: New York, USA. pp 331-397.

Sokoloff A (ed) (1974). The Biology of Tribolium with special emphasis on genetic aspects, vol. 2. Oxford University Press: Oxford, UK.

White NDG, Bell RJ (1988). Inheritance of malathion resistance in a strain of Tribolium castaneum (Coleoptera: Tenebrionidae) and effects of resistance genotypes on fecundity and larval survival in malathion-treated wheat. J Econ Entomol 81: 381386.

White NDG, Bell RJ (1990). Relative fitness of malathion-resistant strain of Cryptolestes ferrugineus (Coleoptera: Cucujidae) when development and oviposition occur in malathiontreated and untreated wheat kernels. I Stored Prod Res 26: 23-37.

White NDG, Leesch JG (1996). Chemical control. In: Subramanyam B, Hagstrum DW (eds), Integrated Management of Insects in Stored Products, Marcel Dekker, Inc: New York, USA. pp 287-330.

Williams IS, Haylock LA, Dewar AM, Dixon AFG (1998). Selection for a moderately insecticide resistant clone of Myzus persicae (Hemiptera: Aphididae) on sugarbeet in the absence of pesticides. Bull Entomol Res 88: 653-658. 